\title{
Do Circadian Preferences Influence the Sleep Patterns of Night Shift Drivers?
}

\author{
Fernanda V. Narciso ${ }^{a, b} \quad$ Andrea M. Esteves $^{d} \quad$ Luciana Oliveira e Silva $^{a}$ \\ Lia R.A. Bittencourt ${ }^{b}$ Rogerio S. Silva ${ }^{b}$ Maria Laura N. Pires ${ }^{c}$ Sergio Tufik ${ }^{b}$ \\ Marco Tulio de Mello ${ }^{a, b}$ \\ ${ }^{a}$ Centro Multidisciplinar em Sonolência e Acidentes/Associação Fundo de Incentivo a Pesquisa, ${ }^{b}$ Universidade \\ Federal de São Paulo, São Paulo, 'Universidade Estadual Paulista Júlio de Mesquita Fillho, UNESP, Assis, and \\ ${ }^{\mathrm{d}}$ Faculdade de Ciências Aplicadas, Universidade Estadual de Campinas, Limeira, Brazil
}

\section{Key Words}

Circadian rhythm $\cdot$ Shift work $\cdot$ Sleep

\begin{abstract}
Objective: The objective of this study was to analyze the effect of individual circadian preferences of drivers with fixed night work schedules on sleep patterns. Subjects and Methods: A total of 123 professional drivers, 32 indifferent preference drivers and 91 morning preference drivers of an intermunicipality and interstate bus transportation company were evaluated. All drivers underwent polysomnographic recordings after their shifts. Furthermore, they filled out a questionnaire that contained sociodemographic and health questions. The Horne and Östberg questionnaire was used to assess the subjects' morningness-eveningness preference. Results: The mean age was $42.54 \pm 6.98$ years and 82 $(66.66 \%)$ of the drivers had worked for $\geq 15$ years. A significant effect on rapid eye movement (REM) was observed in the morning preference drivers. They showed an increased sleep latency and an REM sleep percentage of $5 \%$ of the total REM time. This reveals a significant effect on sleep architecture associated with work time. Conclusion: The drivers reported that morning preference had a significant effect on
\end{abstract}

\begin{tabular}{ll}
\hline KARGER & $\begin{array}{l}\text { ( } 2013 \text { S. Karger AG, Basel } \\
\text { 1011-7571/13/0226-0571 } \$ 38.00 / 0 \quad \text { Karger }\end{array}$ \\
E-Mail karger@karger.com & $\begin{array}{l}\text { This is an Open Access article licensed under the terms of the } \\
\text { www.karger.com/mpp }\end{array}$ \\
& $\begin{array}{l}\text { Creative Commons Attribution-NonCommercial 3.0 Un- } \\
\text { ported license (CC BY-NC) (www.karger.com/OA-license), } \\
\text { applicable to the online version of the article only. Distribu- } \\
\text { tion permitted for non-commercial purposes only. }\end{array}$
\end{tabular}

their sleep pattern indicating less REM sleep and longer REM sleep latency in the morning preference group. Thus, it is important to evaluate interactions between individual aspects of health and other parameters, such as sleep quality and work organizational factors, to promote night shift workers' health and well-being.

C 2013 S. Karger AG, Basel

\section{Introduction}

In recent decades, there has been a growing interest in the effects of shift work and night shifts on workers' health and quality of life $[1,2]$. Several studies have reported negative effects of shift work and night shifts on health, as well as possible workplace mistakes and increased accident risk due to fatigue [3-5]. The chronic inversion in sleep patterns caused by shift work can lead to circadian rhythm misalignment or desynchronization, which can cause sleep disorders and significant reductions in sleep duration, architecture and quality $[4,6]$.

In an evaluation of 613 employees at a Japanese nuclear plant, Smith et al. [7] reported that individuals with morning chronotype showed greater sleepiness at night, 
were less tolerant of night work, and ingested stimulants to stay awake. Seo et al. [8] showed that morning-type individuals had increased sleepiness during night work.

Some studies $[9,10]$ have reported that morning and indifferent preference individuals tend to have a shorter latency to fall asleep than evening chronotype individuals. Morning preference individuals have a higher increase in sleep pressure during extended wakefulness, shorter sleep duration, greater sleep debt, and the presence of sleep and mood disorders.

In addition, Taillard et al. [9] and Mongrain and Dumont [10] have reported that morning preference individuals prefer to perform their daily activities during the morning period because they feel better in terms of performance, attention and alertness. At night, they prefer to rest and sleep.

The hypothesis of this study was that individual circadian preference (chronotype) can influence the sleep patterns of drivers with fixed night work schedules, especially morning drivers, due to the chronic inversion between the endogenous circadian rhythms and sleep time.

Thus, the purpose of this study was to analyze the effect of individual circadian preferences of drivers with fixed night work schedules on sleep patterns.

\section{Subjects and Methods}

The study included 123 professional male drivers of an intermunicipality and interstate bus transportation company who worked in fixed night shifts (schedule $4 \times 2$ ). The sample consisted of 32 indifferent preference drivers and 91 morning preference drivers. The night shift began at 10 p.m. and finished at 6 a.m. (8hour duration). The study procedures were approved by the Ethics in Research Committee of the Sao Paulo Hospital, Federal University of Sao Paulo, SP, Brazil (ref. 1267/03). The subjects were informed about the study procedures and signed an informed consent for participation. To be included in the study, the drivers must have been hired by the bus company and regularly driven 1 of 32 travel routes. All enrolled drivers underwent a polysomnographic (PSG) examination and completed the administrative questionnaire. They were warned on the use of caffeine or any other substance with possible sedative effects or any other alternatives before the PSG examination.

\section{Experimental Design}

After their night shift, drivers immediately went from the company's central garage situated in the city of Sao Paulo to the Sleep Institute. All evaluated drivers had previously worked for at least 4 consecutive days, with work shifts lasting for $8 \mathrm{~h}$. The PSG evaluations (daytime period) were initiated no more than $120 \mathrm{~min}$ after the end of the work shift. The driver was not allowed to nap or fall asleep during the period preceding the PSG examination. The duration of the PSG examination followed the need of each driver.
Upon completion of the PSG recording, each driver filled out a general anamnesis (medical and work history) form and a morningness-eveningness questionnaire.

\section{PSG Examination}

The PSG recordings were performed using a digital EMBLA system (EMBLA S7000; Embla Systems Inc., Colo., USA). The electroencephalogram (C3-A2, C4-A1, O1-A2, O2-A1), electrooculogram (LOC-A2, ROC-A1), electromyogram (chin and anterior tibial muscles), electrocardiogram, airflow (thermal sensor), thoracic-abdominal movements, snoring (detected by a microphone placed on the lateral neck), pulse oximetry, and body position were monitored simultaneously and continuously. The sleep stages were scored using Rechtschaffen and Kales criteria [11], and electrode placement was performed according to the international 10-20 system [12]. Thirty-two increments were staged according to standard criteria and were visually inspected by the sleep specialist. The following parameters were analyzed: (a) total sleep time (TST) in minutes, defined as the actual time spent asleep; (b) sleep latency in minutes, defined as the time from lights out to the onset of three consecutive epochs of stage 1 or deeper sleep; (c) sleep efficiency, defined as the percentage of total recording time spent asleep; (d) wake time after sleep onset (WASO) in minutes, defined as the total time scored as wakefulness between sleep onset and final awakening; (e) stages 1-3 and rapid eye movement (REM) sleep, defined as the percentage of TST, and (f) latency to REM, defined as the time from sleep onset until the first epoch of REM sleep.

The apnea-hypopnea index (AHI) was calculated as the sum of apneas and hypopneas per hour of sleep, and drivers with an AHI $\geq 5$ were classified as having a sleep respiratory disorder. Snoring was measured with a microphone $[13,14]$.

Anamnesis. The form consisted of sociodemographic and health questions. In addition, body weight in kilograms and height in meters were measured using a digital scale and a stadiometer to calculate the body mass index (BMI).

Individual Circadian Preferences (Chronotype). The Horne and Östberg questionnaire validated for the Brazilian population [15] was used to characterize subjects' morningness-eveningness preference.

\section{Statistical Analysis}

Statistical analysis was performed with the statistical software package (PASW Statistics for Windows, version 18.0; SPSS Inc., Chicago, Ill., USA). Descriptive statistics were used. The data are presented as the mean \pm SD and absolute and relative frequency. Nonparametric data were standardized using z-scores.

To evaluate the effect of circadian preference adjusted for age and $\mathrm{AHI}$ on the sleep pattern of drivers during a night shift schedule, multiple linear regressions was performed. A $p$ value of $<0.05$ was considered to be statistically significant.

Multiple regression analyses were used to determine the effect of circadian preference on sleep patterns of drivers during the night shift schedule. An exploratory analysis was conducted to show the effect of years of shift work on BMI and sleep patterns. However, the regression model presented in table 1 does not include these variables, as there has been weighted multicollinearity between the variables, according to the Durbin-Watson test. Based on previous reports $[16,17]$ on the effect of sleep apnea (assessed by AHI) and age on sleep patterns, the model for the covariate age and $\mathrm{AHI}$ was adjusted. 
Table 1. Effect of circadian preference adjusted for age on the sleep pattern of drivers during a night work schedule

\begin{tabular}{|c|c|c|c|c|c|}
\hline $\begin{array}{l}\text { De- } \\
\text { pendent } \\
\text { variables }\end{array}$ & $\begin{array}{l}\text { Values } \\
\text { of sleep } \\
\text { architecture }^{1}\end{array}$ & & $\beta$ & $\mathrm{t}$ & $\mathrm{p}$ \\
\hline \multirow[t]{3}{*}{ REM } & \multirow[t]{3}{*}{$17.50 \pm 0.63$} & Age & -0.010 & -0.117 & 0.907 \\
\hline & & Chronotype & -0.344 & -3.885 & $0.000^{*}$ \\
\hline & & AHI & 0.190 & 2.227 & 0.028 \\
\hline \multirow[t]{3}{*}{ Efficiency } & \multirow[t]{3}{*}{$79.24 \pm 1.14$} & Age & -0.030 & -0.313 & 0.755 \\
\hline & & Chronotype & -0.133 & -1.413 & 0.160 \\
\hline & & AHI & 0.133 & 1.463 & 0.146 \\
\hline \multirow{3}{*}{$\begin{array}{l}\text { Awake } \\
\text { time }\end{array}$} & \multirow[t]{3}{*}{$57.84 \pm 3.75$} & Age & 0.081 & 0.853 & 0.395 \\
\hline & & Chronotype & 0.069 & 0.735 & 0.464 \\
\hline & & AHI & -0.143 & -1.566 & 0.120 \\
\hline \multirow[t]{3}{*}{ WASO } & \multirow[t]{3}{*}{$80.95 \pm 4.20^{*}$} & Age & -0.050 & -0.546 & 0.586 \\
\hline & & Chronotype & -0.019 & -0.211 & 0.833 \\
\hline & & AHI & 0.327 & 3.744 & 0.000 \\
\hline \multirow[t]{3}{*}{ Arousal } & \multirow{3}{*}{$14.72 \pm 0.66$} & Age & -0.036 & -0.396 & 0.693 \\
\hline & & Chronotype & 0.026 & 0.285 & 0.776 \\
\hline & & AHI & 0.315 & 3.588 & 0.000 \\
\hline \multirow[t]{3}{*}{ TST } & \multirow[t]{3}{*}{$344.51 \pm 6.73$} & Age & -0.082 & -0.864 & 0.389 \\
\hline & & Chronotype & -0.066 & -0.700 & 0.486 \\
\hline & & $\mathrm{AHI}$ & 0.120 & 1.319 & 0.190 \\
\hline \multirow[t]{3}{*}{ Latency } & \multirow[t]{3}{*}{$12.90 \pm 1.23$} & Age & 0.128 & 1.348 & 0.180 \\
\hline & & Chronotype & 0.014 & 0.147 & 0.883 \\
\hline & & AHI & -0.062 & -0.678 & 0.499 \\
\hline \multirow{3}{*}{$\begin{array}{l}\text { REM } \\
\text { latency }\end{array}$} & \multirow[t]{3}{*}{$97.17 \pm 5.58^{*}$} & Age & 0.127 & 1.349 & 0.180 \\
\hline & & Chronotype & 0.229 & 2.448 & $0.016^{*}$ \\
\hline & & AHI & -0.091 & -1.021 & 0.309 \\
\hline \multirow[t]{3}{*}{ Stage 1} & \multirow{3}{*}{$3.13 \pm 0.31$} & Age & 0.111 & 1.173 & 0.243 \\
\hline & & Chronotype & -0.058 & -0.612 & 0.542 \\
\hline & & AHI & -0.124 & -1.354 & 0.178 \\
\hline \multirow[t]{3}{*}{ Stage 2} & \multirow[t]{3}{*}{$49.66 \pm 0.91$} & Age & 0.077 & 0.806 & 0.422 \\
\hline & & Chronotype & 0.091 & 0.954 & 0.342 \\
\hline & & AHI & 0.021 & 0.224 & 0.823 \\
\hline \multirow[t]{3}{*}{ Stage 3} & \multirow[t]{3}{*}{$7.37 \pm 0.23$} & Age & -0.119 & -1.274 & 0.205 \\
\hline & & Chronotype & 0.132 & 1.412 & 0.161 \\
\hline & & AHI & -0.175 & -1.941 & 0.055 \\
\hline \multirow[t]{3}{*}{ Stage 4} & \multirow[t]{3}{*}{$17.26 \pm 0.61$} & Age & -0.116 & -1.220 & 0.225 \\
\hline & & Chronotype & 0.087 & 0.919 & 0.360 \\
\hline & & AHI & -0.025 & -0.275 & 0.783 \\
\hline
\end{tabular}

$* \mathrm{p} \leq 0.05$ multiple linear regression.

${ }^{1}$ Data are presented as mean \pm SD.

Circadian Preferences and Sleep Patterns
Table 2. Participant characteristics

\begin{tabular}{lc}
\hline Characteristics & \\
\hline Age, years & $42.54 \pm 6.98$ \\
BMI & $27.52 \pm 3.88$ \\
AHI, events/h & $6.66 \pm 6.31$ \\
Indifferent preference drivers & $32(26.00)$ \\
Morning preference drivers & $91(74.00)$ \\
Overweight defined as BMI $\geq 25$ & $50(40.65)$ \\
Work time $\geq 15$ years & $82(66.66)$ \\
Men & $123(100)$ \\
\hline \multicolumn{2}{c}{ Values are expressed as mean \pm SD or as n (\%). } \\
\hline
\end{tabular}

\section{Results}

The mean age was $42.54 \pm 6.98$ years and 82 drivers $(66.66 \%)$ had worked for $\geq 15$ years. The descriptive data are shown in table 2 . The effect of circadian preference adjusted for age and AHI on the sleep pattern of drivers during a night work schedule is given in table 1. Morning preference had a significant effect on sleep pattern showing increased REM sleep latency and decreased percentage of REM sleep in the morning preference group.

\section{Discussion}

In this study, the morning preference of the night shift drivers had a significant effect on REM sleep, with increased REM sleep latency and decreased percentage of REM sleep during daytime sleep (after working hours) in the morning preference group. The morning drivers were more affected in their REM sleep, which has an influence on mental and physical restoration, as compared to indifferent preference drivers. These observations confirmed those of previous studies that REM sleep has a positive effect on mood, learning and memory consolidation $[18,19]$.

Moreover, the current study confirmed the previous findings by Carrier et al. [20] who reported that morning preference was associated with decreased REM activity and shorter REM sleep stages (measured in minutes and percentages). However, others studies showed different results [3, 21]. Santos et al. [3] reported shorter sleep latency, lower sleep efficiency and a greater number of interruptions in bus drivers who slept during daytime compared to drivers who slept at night. In their study, Fer- 
nandes Jr. et al. [21] observed no significant difference on sleep latency between shift workers. However, these studies showed changes on sleep patterns.

A number of individual factors may be associated with sleep quality, sleep deprivation and sleep disorders. The circadian preference, for example, can affect tolerance to work, alertness, performance and sleep architecture $[22,23]$.

Several publications have reported that morning-type individuals have a stronger increase in homeostatic sleep pressure with prolonged periods of wakefulness (work) $[9,10]$. The night workers' sleep period mostly occurs during the day and is considered an inappropriate circadian time to sleep because in the morning an endogenously decrease of melatonin occurs. Furthermore, increased core body temperature and peak cortisol secretion may impair daytime sleep $[24,25]$.

In addition, the literature shows that the morning-type individuals prefer sleep at night and perform their activities of leisure and daily living during the day $[9,15,20]$ such as physical activity, social and domestic work. Therefore, these endogenous characteristics and social's life preference can modify the sleep parameters and lead to insufficient sleep recovery during daytime. Takahashi et al. [26] revealed a cycle of dissatisfaction with shift work, physical and psychosocial disorders, fatigue, sleep disorders, and decreased task performance.

This study has several limitations. First of all, it had a cross-sectional design and only employed one subjective method to evaluate the circadian preference; however, we could not compare another group of circadian preference (i.e. evening subjects) because evening-type subjects could not be found in the sample. Maybe we could have discovered different sleep parameters between the three samples of bus drivers (morning, indifferent and evening preference) and identify their (evening preference) sleep patterns. In addition, we could not perform the PSG habituation due to work schedule. All evaluated drivers had previously worked for at least 4 consecutive days, with the work shifts lasting $8 \mathrm{~h}$. The fact that morning preference is associated with REM sleep during daytime sleep does not necessarily mean that it has a negative effect on sleep quality. This can influence the findings concerning REM sleep in this sample. Therefore, it was an important limitation of this study, once the average values of circadian preference assessed by our questionnaire were utilized.

Furthermore, the study did not have a control group and drivers' data were not compared with normative values of literature or with each other, especially for the PSG examination. However, this study facilitates further re-

search on shift work sleep and its relation to life habits and overall workers' health.

Moreover, the focus of the present study was not to report the implementation of intervention programs; however, several studies have shown that implementation of intervention programs to prevent adverse consequences for workers' physical and mental health is important. Naps [27], physical exercise [28], sleep hygiene [29], sleep disorder treatment [30] and anchor sleep are often reported to be good preventive and therapeutic strategies for improving rest and restorative sleep and promoting workers' health $[27,29]$.

\section{Conclusion}

In night shift workers of the morning preference group with decreased REM percentage and increased REM sleep latency, morning preference had a significant effect on the pattern of sleep, especially REM sleep. Thus, it is important to evaluate interactions between individual aspects of health and other parameters, such as sleep quality and work organizational factors, to promote night shift workers' health and well-being.

\section{Acknowledgments}

This work was supported by grants from the Universidade Federal de São Paulo, Associação Fundo de Incentivo à Pesquisa, Fundo de Amparo à pesquisa do Estado de São Paulo (FAPESP), Centro Multidisciplinar em Sonolência e Acidentes (CEMSA)/Fundo de Incentivo á Pesquisa (AFIP), Conselho Nacional de Desenvolvimento Científico e Tecnológico $(\mathrm{CNPq})$ and Centro de Estudo em Psicobiologia e Exercício (CEPE).

References

Med Princ Pract 2013;22:571-575 DOI: $10.1159 / 000354104$
Narciso/Esteves/Oliveira e Silva/Bittencourt/ Silva/Pires/Tufik/de Mello 
6 Colten HR, Altevogt BM: Sleep Disorders and Sleep Deprivation: An Unmet Public Health Problem. Institute of Medicine (US) Committee on Sleep Medicine and Research. The National Academies Collection: Reports funded by National Institutes of Health. Washington, National Academies Press, 2006.

7 Smith L, Tanigawa T, Takahashi M, et al: Shiftwork locus of control, situational and behavioural effects on sleepiness and fatigue in shiftworkers. Ind Health 2005;43:151170 .

8 Seo YJ, Matsumoto K, Park YM, et al: The relationship between sleep and shift system, age and chronotype in shift workers. J Biol Rhythm Res 2000;31:559-579.

-9 Taillard J, Philip P, Coste O, et al: The circadian and homeostatic modulation of sleep pressure during wakefulness differs between morning and evening chronotypes. J Sleep Res 2003;12:275-282.

10 Mongrain V, Dumont M: Increased homeostatic response to behavioral sleep fragmentation in morning types compared to evening types. Sleep 2007;30:773-780.

11 Rechtschaffen A, Kales A: A Manual of Standardized Terminology, Techniques, and Scoring System for Sleep Stages of Human Subjects. Washington, Public Health Service, US Government Printing Office, 1968.

12 Jasper HH: The ten twenty electrode system of the International Federation. Eletroenceph Clin Neurophysiol 1958;10:371-375.

$\checkmark 13$ American Sleep Disorders Association and Sleep Research Society (ASDA): EEG arousals: scoring rules and examples. Sleep1992;15: 173-184.
14 American Academy of Sleep Medicine Task Force: Sleep-related breathing disorders in adults: recommendations for syndrome definition and measurement techniques in clinical research. Sleep 1999;22:667-689.

15 Benedito-Silva AA, Menna-Barreto L, Marques N, et al: A self assessment questionnaire for the determination of morningnesseveningness types in Brazil. Prog Clin Biol Res 1990;341B:89-98.

16 Siddiqui F, Walters AS, Goldstein D, et al: Half of patients with obstructive sleep apnea have a higher NREM AHI than REM AHI. Sleep Med 2006;7:281-285.

17 Koyama RG, Esteves AM, Oliveira e Silva L, Lira FS, Bittencourt LR, et al: Prevalence of and risk factors for obstructive sleep apnea syndrome in Brazilian railroad workers. Sleep Med 2012;13:1028-1032.

18 Stickgold R, Hobson JA, Fosse R, et al: Sleep, learning, and dreams: off-line memory reprocessing. Science 2001;294:1052-1057.

19 Siegel JM: The REM sleep-memory consolidation hypothesis. Science 2001;294:10581063.

20 Carrier J, Monk TH, Buysse DJ, et al: Sleep and morningness-eveningness in the 'middle' years of life (20-59y). J Sleep Res 1997;6:230237.

21 De Araújo Fernandes Jr S, Stetner Antonietti L, Saba A, et al: The impact of shift work on Brazilian train drivers with different chronotypes: a comparative analysis through objective and subjective criteria. Med Princ Pract 2013;22:390-396.
22 Saksvik IB, Bjorvatn B, Hetland H, et al: Individual differences in tolerance to shift work - a systematic review. Sleep Med Rev 2011;15:221-235.

23 Gamble KL, Motsinger-Reif AA, Hida A, et al: Shift work in nurses: contribution of phenotypes and genotypes to adaptation. PLoS One 2011;6:e18395.

24 Baehr EK, Revelle W, Eastman CI: Individual differences in the phase and amplitude of the human circadian temperature rhythm: with an emphasis on morningness-eveningness. J Sleep Res 2000;2:117-127.

25 Bailey SL, Heitkemper MM: Circadian rhythmicity of cortisol and body temperature: morningness-eveningness effects. Chronobiol Int 2001;18:249-261.

26 Takahashi M, Iwasaki K, Sasaki T, et al: Worktime control-dependent reductions in fatigue, sleep problems, and depression. Appl Ergon 2011;42:244-250.

27 Sagaspe P, Taillard J, Chaumet G, et al: Aging and nocturnal driving: better with coffee or a nap? A randomized study. Sleep 2007;30: 1808-1813.

28 Youngstedt SD: Effects of exercise on sleep. Clin Sports Med 2005;24:355-365.

29 Stepanski EJ, Wyatt JK: Use of sleep hygiene in the treatment of insomnia. Sleep Med Rev 2003;7:215-225.

30 Komada Y, Nishida Y, Namba K, et al: Elevated risk of motor vehicle accident for male drivers with obstructive sleep apnea syndrome in the Tokyo metropolitan area. Tohoku J Exp Med 2009;219:11-16. 